\title{
ИННОВАЦИОННЫЙ ВЕКТОР РАЗВИТИЯ АВТОМОБИЛЬНОЙ ПРОМЫШЛЕННОСТИ РОССИИ
}

\author{
Е.В. Максютина, А.В. Головкин*
}

Анализируются тенденции развития мирового автомобилестроения и их влияние на автомобильную промышленность России и Беларуси. Предметом анализа является инновационный процесс и скорость введения изменений, связанные с технологиями беспилотного управления транспортом. Отмечаются процессы застоя в легковом автомобилестроении и рост инновационной активности в грузовом сегменте, особенно в сельскохозяйственном машиностроении. Анализируются проблемы развития ПАО «АВТОВАЗ», ПАО «КАМАЗ, «Ростсельмаш», «Гомсельмаш» и МТЗ-ХОЛДИНГ.

Ключевые слова: неоиндустриализация, аддитивные технологии, беспилотный транспорт, автомобильная промышленность, мировая экономика.

JEL-классификация: O10, O14, O25.

DOI: $10.46782 / 1818-4510-2020-2-109-117$

Материал поступил 30.03.2020 2.

\section{О некоторых аспектах неоиндустриализации и реиндустриализации}

Прежде чем мы начнем нашу статью об инновациях в автопроме, хотелось бы высказать мнение о публикации (Тараш, Голоднюк, 2018. С. 108-117). Посвящена статья вопросам неоиндустриализации и реиндустриализации. Авторы установили их отличительные свойства и предлагают разграничить эти понятия. Мы хотели бы высказать свою точку зрения и пояснения по этому вопросу, тем более что коллеги анализируют и ссылаются, в том числе, и на нашу статью «Неоиндустриализация российской экономики на основе технологий четвертой промышленной революции и развития человеческого капитала» ${ }^{1}$. Считаем, что жесткого разграничения данных понятий быть не может. Сегодня, как мы полагаем, количественный показатель выпуска-

${ }^{1}$ Максютина Е.В., Головкин А.В. 2017. Неоиндустриализация российской экономики на основе технологий четвертой промышленной революции и развития человеческого капитала. Научно-технические ведомости Санкт-Петербургского государственного политехнического университета. Экономические науки. Т. 10. № 1. С. 43-52. емой продукции является основным критерием. Для автомобильной промышленности сейчас это количество выпускаемых автомобилей. Например, в начале 2000-х годов АВТОВАЗу удалось выйти на выпуск автомобилей «Лада» примерно 960 тыс. автомобилей и автокомплектов. Сейчас наблюдается другая ситуация, и хорошо если выпуск в этом году составит 350 тыс. Здесь, казалось бы, нужно говорить о процессе реиндустриализации наверстывания, восстановления производства, но с течением времени изменились условия. Появился каршеринг, из-за которого снизилось производство автомобилей. Также набирает силу тенденция развития беспилотного транспорта. На вопрос, когда АВТОВАЗ опять выйдет на выпуск 960 тыс. автомобилей и автокомплектов, ответа нет. Скорее всего никогда. Это просто не нужно. Получается, что реиндустриализация не закончится никогда? Но инновационные процессы, несмотря на все трудности на заводе, идут ${ }^{2}$.

${ }^{2}$ Максютина Е.В., Головкин А.В. 2017 Автомобильная промышленность: проблемы и их решение в контексте четвертой промышленной революции. Экономист. № 9 . C. $32-41$.

* Максютина Елена Владимировна (lena.betty@mail.ru), кандидат экономических наук, Набережночелнинский институт Казанского федерального университета (г. Набережные Челны, Россия);

Головкин Алексей Вячеславович (bear2003@inbox.ru), ПАО «АВТОВАЗ» (г. Тольятти, Россия). 
Процессы инновационного развития не останавливаются, несмотря на все структурные изменения, происходящие на предприятии. Технологии Big Data внедряются в производство. Они показали свою эффективность в конструкторских разработках. При проектировании автомобиля задаются параметры многоуровневой матрицы, которая состоит более чем из ста тысяч требований к продукту в целом и его компонентам. Берутся такие цифры, поскольку современный автомобиль состоит примерно из десяти тысяч деталей, может чуть меньше, в зависимости от марки автомобиля. Соответственно каждая деталь имеет тоже свои параметры. Математическая модель работает с триллионами разнообразных данных на входе и на выходе, что позволяет в десятки раз уменьшить количество натуральных испытаний автомобилей. Сейчас даже отказались от трековых испытаний товарных автомобилей, все проходит в цеху на специальных стендах.

Цифровизация внедряется во все технологические цепочки производства. Введен электронный оборот технической документации и математических моделей деталей автомобиля. Есть программы, позволяющие отслеживать выполнение распоряжений и приказов. Можно говорить, что в какой-то мере искусственный интеллект помогает руководить предприятием. Также работают программы для складского хозяйства, бухгалтерского учета и других сфер производства, всех их не перечесть. Цифровизация широкомасштабно внедряется в производственный процесс, что помогает предприятию держаться «на плаву», несмотря на количественное снижение выпуска автомобилей. Структурные изменения, хоть и с различными сложностями и противоречиями, все же идут в технологическом процессе, управлении и других сферах деятельности предприятия.

И здесь мы вправе, на наш взгляд, говорить о процессах неоиндустриализации. Из старых укладов производства прорастают новые ростки шестого уклада. И этот процесс нельзя разделить, он непрерывный. Останется ли предприятие, переродившись во что-то новое, или прекратит свою работу, покажет время. Поэтому мы говорим о неоиндустриализации, как технологическом перевооружении производства, не затрагивая показатель количества произведенной продукции.

Сейчас инновационным развитием ПАО «АВТОВАЗ» занимается зарубежная ТНК. Считаем, что должна быть взвешенная промышленная политика государства, потому что в ряде случаев интересы зарубежных ТНК противоречат интересам государства ${ }^{3}$.

Что касается «синхронности изменения экономических отношений», у нас немного другая позиция. Мы в большей мере практики, и смотрим на эти вещи не только под углом академической науки, но и производственной деятельности. Конечно, в идеальном варианте хорошо было бы, если бы существовала промышленная политика государства, получившая приоритетное значение в экономике страны, и можно было, как в административно-плановой системе, синхронно менять экономические отношения. Но в существующих реалиях такого произойти не может. Поэтому мы за постепенность, поступательность и последовательность в движении. Можно сказать, за разные скорости в неоиндустриализации страны.

Но главный вопрос, в каких условиях будет проходить неоиндустриализация? И здесь мы подходим к жизненно важным изменениям в геополитике, которые происходят на волне кризиса расширенного воспроизводства. Полагаем, что именно кризисные явления, которые наступят, по нашим оценкам после 2020-2021 года, будут спусковым крючком для неоиндустриализации страны и мира в целом.

Началом этого процесса послужили события последнего времени, связанные с распространением COVID-19, который может стать механизмом свертывания процессов глобализации.

Герман Греф, выступая на Восточном экономическом форуме - 2018, признал, что «мир глобальным не случился. Может, он и случится, но мы пройдем через сложный период, в котором сейчас находимся, -

${ }^{3}$ Максютина Е.В., Головкин А.В. 2017. Автомобильная промышленность: проблемы и их решение в контексте четвертой промышленной революции. Экономист № 9. C. $32-41$. 
фрагментации, сегментации, национализма, регионализации» ${ }^{4}$.

Что мы можем получить в результате сегментации мировой экономики в автопроме? Развал в поставках комплектующих и компонентов для производства автомобильной техники. Как можно выйти из этой ситуации? Кооперироваться с региональными поставщиками, где это возможно, и налаживать свое производство на новых инновационных подходах.

Это будет ускоренная смена старых укладов на новые, уход предприятий индустриальной эпохи, основанных на глубоком разделении труда. На первый план будут выходить технологии четвертой промышленной революции: промышленный Интернет, роботизация, аддитивные технологии. И здесь нам близок подход профессора С.А. Толкачева (2015, С. 35$)$ о том, что «производство перестает быть сложнейшей управленческой системой, основанной на длинной технологической и логической цепочке поставщиков и потребителей промежуточной продукции» (Толкачев, 2015, C.35).

Такие изменения могут вызвать существенное обострение проблемы безработицы. Но мы видим решение этого вопроса в новом аддитивном способе производства. Мир должен взять на вооружение старый лозунг и вложить в него новый смысл, и перейти, где это возможно, «от массового производства к производству масс».

\section{Аддитивные производства - новые вызовы цифровой эпохи}

Остановимся более подробно на аддитивном способе производства, потому что считаем его важным в будущих экономических отношениях, в том числе и для автомобильной промышленности. Мы постарались сделать свою классификацию будущих аддитивных предприятий, которая отличается от «Фабрик будущего», в которых не только аддитивный способ производства. Национальная технологическая инициатива (НТИ) делит «Фабрики будущего» на три категории:

${ }^{4}$ URL: https://www.vedomosti.ru/finance/articles/ 2018/09/12/780655-konkurentsii-iskusstvennim-intellektomne-viderzhim
1. «Цифровая Фабрика» (Digital Factory) - характеризуется использованием технологий цифрового моделирования и проектирования.

2. «Умная Фабрика» (Smart Factory) формируется на основе «Цифровой Фабрики» с добавлением 3D-принтеров, станков с числовым программным управлением (ЧПУ), робототехнических комплексов и другого высокотехнологичного оборудования.

3. «Виртуальная Фабрика» (Virtual Factory) - формируется как распределенная сеть «Цифровых» и «Умных» Фабрик, а также поставщиков услуг и компонентов.

Целью создания этих фабрик является проектирование и производство высококонкурентной технологичной продукции.

Мы же попытались расширить эту классификацию и ввести градацию будущих аддитивных предприятий:

крупные предприятия - созданные в основном на базе заводов индустриальной эпохи, которые формируются на базе робототехнических комплексов, гибридных станков с ЧПУ, безлюдных цехов и производств с максимальным разнообразием сырьевых материалов;

средние предприятия - аддитивные ателье или бюро. Характеризуются высокопроизводительным и точным аддитивным оборудованием. Выпускают нишевые продукты. Разнообразие сырьевых материалов в них невелико. На предприятии работают несколько человек;

индивидуальные предприниматели и самозанятые граждане. Они применяют бюджетное оборудование. Используются, как правило, один или несколько сырьевых материалов. Качество продукта низкое. Выпуск продукции для себя или мелкой торговли.

Но самое интересное в этой классификации, что все эти предприятия, изначально цифровые, могут использовать сетевую структуру Интернета. Они будут сотрудничать как «Виртуальная Фабрика». О наступающей «эре сотрудничества» говорил американский экономист Джереми Рифкин (2014).

Но наряду с положительным эффектом будут наблюдаться негативные тенденции и вызовы. Эти предприятия будут образовывать неустойчивые альянсы для вы- 
полнения одного или двух заказов. Такие понятия, как штат предприятия, структура, время работы и т. д. будут размываться. Все будет неустойчиво и аморфно. Зачастую производитель, изготавливая компоненты, не будет знать, какая продукция в итоге получится и к каким последствиям это приведет. Это, на наш взгляд, является серьезным дестабилизирующим фактором.

Наиболее подверженной манипуляциям, с нашей точки зрения, является третья группа индивидуальных предпринимателей и самозанятых граждан, к которым будут активно присоединятся подростки, использующие 3D-принтеры. И это новое явление для производственного процесса.

Для описания этого процесса мы ввели новые понятия: предприятия Smart Mob Factory и Flash Mob Factory. Smart Mob Factory - это предприятие, которое для производства продукции будет на принципах краудсорсинга привлекать широкий круг индивидуальных предпринимателей по типу субподрядной работы с применением инфокоммуникационных технологий (в режиме онлайн).

Разновидностью Smart Mob Factory может быть Flash Mob Factory, отличительной чертой которой является ограниченное время существования. Данные образования будут существовать только для выполнения одного или нескольких заказов. Количество индивидуальных предпринимателей в таких предприятиях может быть гигантским. Это можно сравнивать с роем пчел, умной пылью, стаей, стадом и т. д.

По нашему мнению, предприятия типа Smart Mob Factory и Flash Mob Factory будут являться серьезным дестабилизирующим фактором мирового рынка для предприятий второй промышленной революции. Перепроизводство продукции в отдельном регионе будет происходить подобно вспышкам.

Становится понятно, для чего нужна регионализация и сегментация в мире. Разделение нужно для естественного отбора, как это происходит в природе. Какие экономические отношения сумеют приспособиться к новым условиям развития, по такому пути и пойдет развитие цивилизации. Но это проблемы будущего.

\section{Тренды мирового автопрома}

Мировая автомобильная промышленность стоит на пороге кардинальных перемен. Связаны они с наступлением шестого уклада технологического цикла. В своей книге Джереми Рифкин (2014) выделил пять принципов, по которым должна развиваться новая стратегия развития: 1) переход на возобновляемые источники энергии; 2) превращение всех зданий в мини-электростанции; 3) использование водородной энергии; 4) использование интернет-технологий; 5) производство электромобилей. Несмотря на то, что третья промышленная революция еще далеко не распространилась по миру, она перерастает в четвертую индустриальную революцию.

Все эти принципы в разной степени будут влиять на развитие мирового автопрома. И мы начнем с первой технологии перехода на возобновляемые источники энергии. В феврале 2018 г. компании Lockheed Martin удалось получить патент на компактный термоядерный реактор, который «может уместиться в кузове грузовика», мощностью 100 МВт. Анонсируется создание рабочего образца этого реактора к 2024 г.

Но и в использовании водородной энергии достигнуты существенные результаты. Так исследователи из Университета имени Бен-Гуриона и Техниона (Израильский технологический институт) открыли химический механизм, который поможет в разработке нового и более эффективного фотохимического процесса для создания водородного топлива из воды. Об этом пишет Naked Science со ссылкой на статью, опубликованную в журнале «Nature Communications». «Это открытие может серьезно повлиять на попытки заменить углеродное топливо более экологичным водородным, - рассказывают исследователи. - Производители автомобилей хотят делать машины, работающие на водороде, так как они считаются более мощными и экологичными, а также, в отличие от электромобилей, их можно быстро заправить и проезжать большие расстояния ${ }^{5}$. Здесь надо уточнить, что вектор движения в сто-

${ }^{5}$ URL: https://naked-science.ru/article/sci/uchenyedostigli-proryva-v

112 Белорусский экономический журнал № $2 \bullet 2020$ 
рону водородного двигателя мы наблюдаем в основном у японских автопроизводителей.

Bсе это говорит о том, что мы находимся в шаге от завершения эры углеводородов. По какому пути пойдет развитие мирового автопрома? Будет ли это водородный двигатель или электрический?

Похоже, США уже определились с вектором своего движения. Они продолжат развитие в соответствии с теорией Джереми Рифкина, а магистральным направлением выбрано создание электромобилей. Под этот проект в настоящее время начинает создаваться инфраструктура. Но средств, как обычно, не хватает. Для этого был предпринят оригинальный ход - оплачивать перевооружение страны должны немецкие автоконцерны под видом штрафов.

Как мы помним, дизельный скандал разгорелся осенью 2015 г. Тогда по данным газеты «The New York Times», концерн Volkswagen AG был уличен в подтасовке данных по содержанию вредных веществ в выхлопах дизельных автомобилей. Данные занижались путем манипуляции с программным обеспечением. Общие затраты концерна из-за дизельного скандала составили около 20 млрд долл. США.

В июле 2017 г. журнал «Der Spiegel» сообщал, что в 1990-е годы Daimler, BMW, Volkswagen, Porsche и другие автоконцерны осуществляли сговор в крупных масштабах относительно техники, цен, поставщиков, рынков и стратегий6. Если эти подозрения подтвердятся, то данный картельный сговор станет одним из крупнейших за всю историю немецкой экономики.

Эта жесткая линия поведения была продолжена и президентом США Дональдом Трампом. В интервью немецкой газете «Bild» он подверг резкой критике немецких автопроизводителей: «Хотите производить автомобили по всему миру? Желаю вам всего хорошего. Вы можете собирать автомобили для Соединенных Штатов, но за каждый автомобиль, привезенный в США, вы будете платить 35-процентный налог» ${ }^{7}$. Есть и другие высказывания по-

\footnotetext{
6 URL: https://www.interfax.ru/world/584115

7 URL: https://vz.ru/economy/2017/1/16/853567.html
}

добного рода. Цель довольно ясна. Американцы берут деньги там, где они есть. Возможно, следующим «пострадавшим» может оказаться Япония. Так как экономики Германии и Японии генерируют положительный денежный поток в наибольшей степени, поэтому претензии направлены в их адрес. Важно подчеркнуть, что такого рода скандалы происходят в странах с ограниченным суверенитетом. В то же время в Китае, где претензий значительно больше, никаких осложнений не наблюдается.

Но есть и другие вызовы для мирового автопрома. Это каршеринг, который может существенно повлиять на массовое производство автомобилей в сторону уменьшения, и набирающая силу тенденция к беспилотному транспорту.

\section{О российском автопроме}

Переходя к российским реалиям нужно понимать, где мы находимся по сравнению с другими мировыми производителями в данный момент времени.

Такую возможность нам дал теперь уже бывший вице-президент «АВТОВАЗа» по инжинирингу Харальд Грюбель, который дал откровенное интервью изданию «Авторевю». По его словам, российская автомобильная промышленность откатилась к первому уровню развития, который заключается в том, что в стране почти не осталось собственного инжиниринга, а автозаводы занимаются сборкой автомобилей на иностранных платформах с некоторым уровнем локализации (в среднем 40\%). Автопром СССР находился на третьей ступени развития (собственные ноу-хау, инжиниринг и производство), а современные развитые страны находятся на высшем четвертом уровне, который предполагает не только свои платформы и производство, но и массовый экспорт.

Но самое важное, что сделал Харальд Грюбель, смог высказать идею реформирования российского автопрома, предложив всем работающим в России выпускать автомобили разных брендов на общей платформе, с унификацией шасси, узлов и компонентов. Эта инициатива не была поддержана. Грюбель был уволен. 
Но мы считаем, что потенциал у этой идеи все же не исчерпан, и к ней можно будет вернуться, когда начнутся процессы регионализации.

Сейчас существенных изменений в конструкции автомобилей не наблюдается, за исключением дизайнерских разработок. Можно говорить о процессах застоя в легковом автомобилестроении России.

На 11 Международной выставке-форуме «Автопром. Автокомпоненты», прошедшей в Тольятти в октябре 2018 г., было заявлено о переходе альянса Renault-NissanMitsubishi на новую промышленную платформу к 2021 г. Там же вице-президент по закупкам ПАО «АВТОВАЗ» Венкатран Мамиллапалле сообщил: «Те модели, которые сейчас находятся в производстве, к 2021 г. значительно изменятся. С внедрением новой промышленной платформы изменится LADA Vesta, изменится весь современный модельный ряд» ${ }^{8}$.

Какие последствия этого решения ожидают ПАО «АВТОВАЗ» и его местных поставщиков? Это приведет к полной утрате компетенций проектирования автомобиля и ликвидации всей цепочки местных поставщиков. Завод превратится в сборочное предприятие.

\section{Об успехах КАМАЗа}

Но не все так грустно в российском автопроме. Нас радуют успехи инновационного развития ПАО «КАМАЗ». Мы связываем это с формой собственности завода и кризисом 2008 г. Кризис помог. Напомним, что к этому времени оба завода, АВТОВАЗ и КАМАЗ, были подготовлены к продаже зарубежному инвестору. В итоге АВТОВАЗ, как наиболее ликвидный актив, был продан, а КАМАЗ не успели продать, так как цены резко снизились. Помог счастливый случай. С тех пор предприятие успешно развивается, этому помогает мировая тенденция по смещению инновационного фокуса в сторону грузового транспорта. Флагманом этого движения выступают технологии беспилотного управления.

Недавно КАМАЗ и НАМИ показали новый автомобиль под названием «Шатл».

8 URL: https://www.autostat.ru/news/36125/
Это что-то среднее между автобусом, такси и легковым автомобилем, будет использоваться как беспилотный транспорт по доставке пассажиров от подъезда дома до пункта назначения. Идея проекта преследует цель снижения транспортной загруженности в городах. С введением таких автомобилей станут лишними фиксированные маршруты и остановки общественного транспорта. Искусственный разум будет рассчитывать рациональные потоки движения, напряженность на дорогах уменьшится.

Однако пока такие автомобили, как «Шатл», и другая беспилотная техника, на дороги общественного пользования выпускаться не будут. Во всем мире еще не разработана нормативная база для использования беспилотного транспорта. Но на закрытых территориях такая возможность появляется.

Так, на территории завода «КАМАЗ» начались тестовые заезды беспилотного автомобиля КАМАЗ-4308. Проект получил название «Одиссей». Грузовик без водителя будет поставлять кабины с прессово-рамного завода на автомобильный. Эти заезды будут проводиться на внутризаводской территории. Кроме того, это может стать первым шагом к роботизации промышленной техники, в том числе работающей в экстремальных условиях крайнего Севера, на шахтах, карьерах и т. д.

Такой проект «КАМАЗ» начал осуществлять в одном из угольных карьеров на шахте «Листвяжная» в рамках реализации другого масштабного проекта «Цифровое горное предприятие». Его итогом должно стать создание целой системы беспилотной перевозки угля в Кузбассе к декабрю 2020 г.

В последнее время в связи со сложной конъюнктурой рынка коммерческого транспорта в России для «КАМАЗа» стало важно развивать выпуск пассажирского транспорта. По этой причине осваивается производство электробусов, первые 100 уже эксплуатируются в Москве. Также особое внимание будет уделяться производству грузовиков и мусоровозов на газовом топливе.

Итак, как указано выше, в мире рассматривают два пути развития автопрома: электромобили и автомобили с водородным двигателем. Для России возможен и тре- 
тий - это технологии, основанные на использовании газа.

Никаких новых конструктивных решений применение газа не требует. Старые платформы к этому прекрасно подходят. Затраты нужны только на структуру газовых станций. И можно наблюдать, чья концепция возьмет верх, к тем и присоединяться, чтобы избежать ненужных затрат.

И еще одна важная миссия, которую должен принять на себя КАМАЗ. По нашему мнению, следует возобновить выпуск легковых автомобилей, как это было с автомобилем «Ока», чтобы сохранить компетенции в легковом автомобилестроении страны, но уже на новой инновационной основе. Мы думаем, что разделение труда в автомобилестроении устарело и нужен обратный процесс соединения. Для этого надо использовать модульный принцип с широкомасштабным применением аддитивных технологий, так как конвейерные системы тоже серьезно устарели. Предложения по этим вопросам мы рассматривали в работах, касающихся внедрения аддитивных технологий на крупных предприятиях страны ${ }^{9}$.

В г. Тольятти компетенции постепенно утрачиваются и передаются за рубеж. Альянс не заинтересован в их развитии и сохранении на АВТОВАЗе. Завод постепенно превращается в сборочное производство автомобилей на устаревших платформах. Да и дальнейшее существование такого Альянса вызывает большие сомнения. Мы считаем, что смещение инновационного фокуса развития автомобилестроения в сторону КАМАЗа должно благоприятно сказаться на будущих разработках и построении новых модульных технологических цепочек производства автомобиля.

\section{Сельскохозяйственное машиностроение в центре инновационных процессов беспилотного управления транспортом}

Фокус инновационной активности в автомобилестроении смещается в грузовой сегмент, но особенная активность наблю-

${ }^{9}$ Максютина Е.В., Головкин А.В. 2017. Неоиндустриализация российской экономики на основе технологий четвертой промышленной революции и развития человеческого капитала. Научно-технические ведомости Санкт-Петербургского государственного политехнического университета. Экономические науки. Т. 10. № 1. С. 43-52. дается в сельскохозяйственном машиностроении.

Одним из флагманов отрасли является российское предприятие «Ростсельмаш». С 2004 г. с ростовчанами сотрудничает «Научно-производственное объединение автоматики», разрабатывающее и поставляющее цифровые системы управления. И если КАМАЗ принимает участие в проекте «Цифровое горное предприятие», то «Ростсельмаш» тоже участвует в большом инновационном проекте «Умное земледелие». Этот проект направлен на массовое использование беспилотных технологий и высокоточной навигации в сельском хозяйстве. Появление такой инновационной системы на полях позволит существенно снизить число задействованных в управлении сельскохозяйственной техникой людей. При этом производительность труда на селе должна увеличиться в разы, а высвобожденные рабочие ресурсы могут ввести в севооборот дополнительные пахотные площади, что позволит нарастить объемы производства сельскохозяйственной продукции. Такие инновационные решения в сельском хозяйстве могут помочь и в реализации космических программ, где цифровое сельское хозяйство может стать заказчиком глобальной спутниковой системы связи «Сфера».

Специалисты из «НПО автоматики» обещают в короткие сроки установить системы беспилотного управления на трактор или комбайн любого производителя. Не нужна даже новая техника, можно использовать старый существующий в хозяйстве парк. И это очень большой плюс.

Установка системы не требует вмешательства в конструкцию машины. Устанавливаются антенны, датчики, контроллер, камера, подруливающее устройство. Таким образом, возможна работа по принципу «роя» сельхозмашин, когда ведущая машина управляется человеком, а за ней следуют ведомые беспилотные комбайны.

«НПО автоматика» сотрудничает не только с российскими производителями, но и с белорусскими предприятиями, в частности с «Гомсельмаш». В Беларуси тоже реализуется проект подобный «Умному земледелию», но называется он «Точное земледелие». Нам это напомнило исполь- 
зуемую в автомобилестроении систему поставок автокомпонентов «точно в срок». Суть точного земледелия проста и определяется как: «применение правильного продукта в правильном количестве, в правильном месте, в правильное время».

Для этого тоже используется беспилотная техника. Помогает продвигать идеи «Точного земледелия» и «МТЗ-ХОЛДИНГ», который на сегодняшний день превратился в одного из крупнейших производителей сельскохозяйственной техники не только в странах СНГ, но и во всем мире. Он представляет свой знаменитый товарный знак «BELARUS» Минского тракторного завода.

Подобные проекты по использованию беспилотной техники имеют большой экспортный потенциал. Мировой рынок интеллектуальных систем для сельского хозяйства, по данным крупнейших мировых маркетинговых агентств, может составить около 4 млрд долл. к 2025 г. Потенциальными импортерами подобных систем могут быть страны СНГ и Индия, которая считается второй страной в мире по количеству плодородных земель. В России полигонами для отработки таких технологий могут стать территории Республики Татарстан, Рязанской, Белгородской и Ярославской областей.

Мы считаем, что направление на развитие беспилотной техники, наряду с другими прорывными технологиями, для России может стать входным билетом в шестой технологический уклад четвертой промышленной революции. Использование цифровых систем и высокоточной навигации в сельском хозяйстве должны сопровождаться ростом показателей в космической отрасли, робототехники, аддитивных технологий, ускорить переход на возобновляемые источники энергии, значительно улучшить экологическую обстановку в стране. Также мы полагаем, что если получится реализовать подобные инициативы, разница качества жизни в городе и деревне постепенно нивелируется. В результате мы получим инновационную, высокотехнологичную «цифровую деревню» шестого уклада.
Таким образом, проведено разграничение понятий неоиндустриализация и реиндустриализация. Неоиндустриализация рассматривается как технологическое перевооружение производства, и важны разные скорости в неоиндустриализации страны.

Для неоиндустриализации и четвертой промышленной революции важны аддитивные технологии. Предложена классифицикация будущих аддитивных предприятий и определены новые вызовы и проблемы, с которыми, возможно, столкнется мировое сообщество при переходе на новый технологический уклад.

Рассмотрены тенденции, происходящие в мировом автопроме и их влияние на развитие автомобильной промышленности России и Беларуси. В результате проведенных исследований сделан вывод о застойных явлениях, наступивших в российском легковом автомобилестроении. В то же время фокус инновационного развития сместился в сторону грузового транспорта, и особенно сельскохозяйственного машиностроения, что связано в первую очередь с технологиями беспилотного управления.

\section{СПИСОК ЛИТЕРАТУРЫ (REFERENCES)}

Рифкин Дж. 2014. Третья промышленная револючия: Как горизонтальные взаимодействия меняют энергетику, экономику, мир в иелом. Москва: Альпина нон-фикшн. [Rifkin J. 2014. The Third Industrial Revolution: How Lateral Power Is Transforming Energy, the Economy, and the World. Moscow: Al'pina non-fikshn. (In Russ.)]

Тараш Л.И., Голоднюк Р.А. 2018. О новой индустриализации и реиндустриализации экономики. Белорусский экономический журнал. № 2. С. 108117. [Tarash L.I., Golodnyuk R.A. 2018. Regarding new industrialization and reindustrialization of economy. Belorusskiy jekonomicheskiy zhurnal. No 2. PP. 108117. (In Russ.)]

Толкачев С.А. (Ред.) 2015. Промышленная политика в условиях новой индустриализации: монография. Москва: МАКС Пресс. [Tolkachev S.A. (Ed.) 2015. Industrial policy in the context of the new industrialization: monograph. Moscow: MAX Press. (In Russ.)] 
In citation: Belorusskiy Economicheskiy zhurnal. 2020. No 2. PP. 109-117.

Belarusian Economic Journal. 2020. No 2. PP. 109-117.

\section{INNOVATIVE VECTOR OF RUSSIA'S AUTOMOBILE INDUSTRY DEVELOPMENT}

\section{Elena Maksyutina ${ }^{1}$, Aleksei Golovkin ${ }^{2}$}

Authors affiliation: ${ }^{1}$ Naberezhnye Chelny Institute of Kazan Federal University (Naberezhnye Chelny, Russia);

${ }^{2}$ PJSC (Public Joint Stock Company) «AVTOVAZ» (Togliatti, Russia).

Corresponding author: Maksyutina Elena (lena.betty@mail.ru).

ABSTRACT. Analyzed are the global automobile manufacturing trends and their impact on Russia's and Belarus's automobile industries. The subject of analysis is the innovative process as well as the rate of introducing changes related to the technologies of remotely piloted vehicles. Stated are stagnation processes in passenger cars manufacturing, and the growth of innovative activity of the trucks manufacturing segment, especially in agricultural machine manufacturing. Analyzed are the development issues of PJSC «AVTOVAZ», PJSC «KAMAZ», «Gomselmash» and MTZ-HOLDING.

KEYWORDS: neoindustrialization, additive technologies, remotely piloted vehicles, automobile industry, world economics.

JEL-code: O10, O14, O25.

DOI: $10.46782 / 1818-4510-2020-2-109-117$

Received 30.03.2020 